\title{
XLVIII. The problem of random flights
}

\section{T.J.I'a. Bromwich Sc.D. F.R.S.}

To cite this article: T.J.I'a. Bromwich Sc.D. F.R.S. (1921) XLVIII. The problem of random flights, Philosophical Magazine Series 6, 42:249, 432-435, DOI: 10.1080/14786442108633779

To link to this article: http://dx.doi.org/10.1080/14786442108633779

$$
\text { 册 Published online: } 08 \text { Apr } 2009 .
$$

Submit your article to this journal

Џll Article views: 6

Q View related articles $\sqsubset$ 
the length on the right-hand side of equation (1) is found to be approximately $1 \cdot 47$ kilometres.

Accordingly, if we suppose that the nnits are chosen so that the two fundamental constants $\gamma$ and $c$ are both expressed by unity, it follows that the mass of the sun is equal to about 1.47 kilometres-an apparently mystical result.

This calculation is given, in substance, in Prof. A. S. Eddington's Report on Relativity*, but it seems to have escaped notice to some extent.

I am, Gentlemen,

St. John's College,

Cambridge.

June 20th, 1921.

Your obedient Servant,

T. J. T'A. B Rомшісн,

Prælector in Mathematics.

XLVIII. The Prollem of Random Flights. By T. J. I'A. Bronwsen, Sc.I)., F.R.S., Fellow and Prolector in Mathematir's, St. John's College, Cambridye †.

QIUDENTS of the late Lord Rayleigh's papers will $O$ recollect that he occupied himself with the above topic on more than one occasion, and one of his last papers $\ddagger$ stimulated my interest in the subject. I have already published a short note $\S$ dealing with the extension of Bernoulli's theorem which is required in the earlier part of the investigation, and I had hoped to have communicated to Lord Rayleigh a method (suggested by the use of Heaviside's operators) for shortening the algebra required in the later part. Unfortunately our correspondence was terminated by Lord Rayleigh's fatal illness, and I have been delayed so far from publishing my account, which will be found below.

\section{The problem of Random Flights in three dimensions.}

For various reasons the discussion of the problem in three dimensions is ensier than in two dimensions, just as the problem of wave-propagation in two dimensions is the more difficult.

* See the footnote on p. 27 ; it may be useful, perhaps, to point out that a more exact form of equation (1) is really

$$
\gamma(\mathrm{S}+\mathrm{E}) / c^{2}=4 \pi^{2} a^{3} /(c \mathrm{~T})^{2}
$$

where 2 " is the major-axis of the earth's orbit and $E$ is the earth's mass.

+ Comunnicated by the Author.

+ Phil. Mag. (6) rol. xxxvii. p. 321 (1919).

$\S$ Phil, Jag. (6) rol. xxxviii. p. 231 (1919). 
Lord Rayleigh has proved * that the chance that the resultant of $n$ flights (each of length $l$ ) may lie between $r$ and $r+d r$ is equal to $4 \pi r^{2} d r$. $\phi_{n}$, where

$$
\phi_{n}=\frac{1}{4 \pi^{2} r l^{n}} \int_{-\infty}^{\infty} \frac{d y}{y^{n-1}} \sin r y(\sin l y)^{n} . \quad . \quad .
$$

On observing this formula it suggested to my mind a corresponding complex integral to which it is at once seen to be equivalent, namely,

where $">0$.

$$
\phi_{n}=\frac{\iota}{4 \pi^{2} r l^{n}} \int_{c-\infty}^{c+\infty} \frac{d \lambda}{\lambda^{n-1}} \sinh r \lambda(\sinh l \lambda)^{n}
$$

In this form the use of Heaviside's symbolical notation is suggested as a convenient abbreriation $\dagger$. In fact, we have

$$
\phi_{n}=\frac{-1}{2 \pi r l^{n}} \frac{1}{p^{n-2}} \sinh l^{r}(\sinh p l)^{n}, \quad . \quad .
$$

where $p$ denotes $\partial / \partial t$ and, after the operations have been curried out, $t$ is put ecyual to zero.

It is now an easy matter to evaluate $\phi_{2}, \phi_{3}, \phi_{4}, \ldots$, by following the process explained in $\$ 6$ of my paper jnst quoted. Thus we find :-

\section{(i.) $n=2$.}

$$
\phi_{2}=\frac{-1}{16 \pi r^{2}}\left(e^{p r}-e^{-p r}\right)\left(e^{p l}-e^{-p l}\right)^{2}
$$

and we are simply to count unity for each exponential which has a positive index on expansion (ignoring those with negative indices) $\ddagger$. Hence (since $0<r_{i}<2 l$ )

$$
\phi_{2}=-\frac{1}{16 \pi r^{2}}(1-1-2)=\frac{1}{8 \pi r^{2}}, \quad .
$$

which agrees with (48) of Lord Rayleigh's paper.

* Phil. Mag. vol. xxxviii. p. 341 (1919) ; formula (59) gires thet integral for $d \mathrm{P}_{n} / d r$, and $4 \pi r^{2} \phi_{n}=d \mathrm{P}_{n} / d r$. The notation $\phi_{n}$ is that adopted by Prot. Karl Pear'son.

$\uparrow$ Bromwich, Proe. Lond. Nath. Soc. (2) vol. xv. p. 401 (1916); see $\$ 4$ in particular.

$\ddagger$ Bromwich, Proc. L. M. S. l. c. p. 425.

Phil. Mag. S. 6. Vol. 42. No. 249. Sept. 1921. $2 \mathrm{G}$ 
(ii.) $n=3$.

$$
\phi_{3}=\frac{-1}{32 \pi r l^{3}} \frac{1}{p}\left(e^{p r}-e^{-p r}\right)\left(e^{p l}-e^{-p l}\right)^{3} .
$$

Here we have to take the formulæ *

$$
\frac{1}{p} e^{p_{s}}=s, \text { if } s>0 ; \frac{1}{p} e^{p_{s}}=0, \text { if } s<0 .
$$

Then the result is

$$
\begin{aligned}
& 0<r<l, \quad \phi_{3}=\frac{-1}{32 \pi r l^{3}}\{(r+3 l)-3(r+l)-(3 l-r) \\
& \quad+3(l-r)\} ; \\
& l<r<3 l, \quad \phi_{3}=\frac{-1}{32 \pi r l^{3}}\{(r+3 l)-3(r+l)+3(r-l)
\end{aligned}
$$

Summing up, we see that

$$
\left.\begin{array}{ll}
\phi_{3}=\frac{1}{8 \pi l^{3}}, & 0<r^{2}<l \\
\phi_{3}=\frac{3 l-r}{16 \pi l^{3}}, & l<r<3 l
\end{array}\right\}, . . .
$$

agreeing with (61) of Lord Rayleigh's paper.

$$
\text { (iii.) } \frac{n=4 .}{\phi_{4}}=\frac{-1}{64 \pi r l^{4}} \frac{1}{p^{2}}\left(e^{p r}-e^{-p r}\right)\left(e^{p l}-e^{-p l}\right)^{4} \text {. }
$$

Here the standard formulæ are

$$
\frac{1}{p^{2}} e^{p s}=\frac{s^{2}}{2}, \text { if } s>0 ; \quad \frac{1}{p^{2}} e^{p_{s}}=0, \text { if } s<0 .
$$

Hence we obtain the results

$$
\begin{gathered}
0<r<2 l, \quad \phi_{4}=\frac{-1}{128 \pi r l^{4}}\left\{(r+4 l)^{2}-4(r+2 l)^{2}+6 r^{2}\right. \\
\left.-(4 l-r)^{2}+4(2 l-r)^{2}\right\} ; \\
2 l<r<4 l, \quad \phi_{4}=\frac{-1}{128 \pi r l^{4}}\left\{(r+4 l)^{2}-4(r+2 l)^{2}+6 r^{2}\right. \\
\left.-4(r-2 l)^{2}-(4 l-r)^{2}\right\} .
\end{gathered}
$$

* Bromwich, Proc. L. M. S. l. c. p. 425. 


$$
\text { Problem of Random Flights. }
$$

These simplify to

$$
\left.\begin{array}{ll}
\phi_{4}=\frac{1}{64 \pi l^{4}}(8 l-3 r), & 0<r<2 l \\
\phi_{4}=\frac{1}{64 \pi r l^{4}}\left(4 l-r^{2}\right)^{2}, & 2 l<r<4 l
\end{array}\right\}, .
$$

agreeing with (62) of Lord Rayleigh's paper.

I do not write out the corresponding calculations for $n=6$; the results depend on the symbolical formulæ

$$
\frac{1}{p^{4}} e^{p s}=\frac{s^{4}}{ \pm !}, \text { if } s>0: \frac{1}{p^{4}} e^{p s}=0, \text { if } s<0 .
$$

The results are stated by Lord Rayleigh in formula (64.) of his paper.

In dealing with the specially interesting problem when $n$ is large, the calculation by symbolical methods gires no substantial variation from the treatment by Lord Rayleigh: see $(65)-(70)$ of his paper.

2. The problem of Random Flights in two dimensions.

After the previous account, it will suffice to treat the present problem rather more brielly. Lord Rayleigh obtains in his formula (32) the result

$$
\phi_{n}\left(r^{2}\right)=\frac{1}{4 \pi} \int_{-\infty}^{\infty} y d y \cdot \mathrm{J}_{0}(r y)\left\{\mathrm{J}_{0}(l y)\right\}^{n} . .
$$

$J$ ust as in $\$ 1$, this may be transformed to the complex integral

where

$$
\phi_{n}\left(r^{2}\right)=\frac{-1}{4 \pi} \int_{c-\imath \infty}^{c+\infty \infty} \lambda d \lambda \mathrm{I}_{0}(r \lambda)\left\{\mathrm{I}_{0}(l \lambda)\right\}^{n}
$$

$$
\mathrm{I}_{0}(z)=1+\frac{z^{2}}{2^{2}}+\frac{z^{4}}{2^{2} \cdot 4^{2}}+2^{2} \cdot 4^{6} \cdot 6^{2}+\ldots
$$

is the modified Bessel-function.

The integral (2.11) can be replaced ly a symbolical formula, but the result is not capable of any simple evaluation. It should be noted, however, that when the integral is written in the form $(2 \cdot 11)$ the questions raised by Lord Rayleigh (l.c. pp. 333-336) as to the legitimacy of differentiation, applied to the integral (2:1), are easily settled.

The discussion of the integral $(2 \cdot 11)$ for large values of $n$ follows the same lines as on p. 337 of Lord Rayleigh's paper. 